\title{
Conditions for Customer Relationship Management (CRM) success in Zimbabwe's Hospitality sector.
}

\author{
Mirimi Kumbirai ${ }^{1}$ and Jakachira Nyasha ${ }^{1}$ \\ ${ }^{1}$ Department of Travel and Recreation, Chinhoyi University of Technology, Zimbabwe. Private Bag 7724, \\ Chinhoyi, Zimbabwe.
}

\begin{abstract}
We investigated the conditions necessary for CRM success in a Hospitality sector that is failing to retain and attract clients. The main purpose of this study was to establish the potential of CRM in aiding customer retention in Zimbabwe's Hospitality sector that has been marred by economic instability and a decade of political turmoil. Our approach was based on a mixed approach of a quantitative and qualitative dimension. Results indicate that operational and technological conditions in place for CRM in Zimbabwe's hospitality sector are somewhat ineffective potentially due to limited resources for technological advancement and reluctant management systems to fully practice CRM. The conclusions thereof emphasise on the need to promote technological integration in the business of the hospitality sector and promote a CRM strategy that take cognisance of customer needs as a drive towards better business performance in Zimbabwe's Hospitality sector.
\end{abstract}

Key words: CRM, CRM success, relationship marketing, service conditions, customer retention.

\section{Introduction}

In the marketing literature the terms customer relationship management and relationship marketing are used interchangeably. These terms have been used to reflect a variety of themes and perspectives. Some of these themes offer a narrow functional marketing perspective while others offer a perspective that is broad and somewhat paradigmatic in approach and orientation [1].

[2] as cited in [3], defined customer relationship management as the organisation's attempt to develop a long term, cost-effective link with the customer for the benefit of both the customer and the organisation. This implies that there is mutual benefit between the company and the customer as it is in relationships. CRM is defined from a balanced perspective by [4] who state that "CRM is the philosophy, policy and coordinating strategy mediated by a set of information technologies, which focuses on creating two way communications with customers so that firms have an intimate knowledge of their needs, wants and buying patterns."

In addition, one of the most recent and holistic definitions of CRM is the definition by [5] cited in [6] suggest that "CRM is the building of a customer-oriented culture by which a strategy is created for acquiring enhancing the profitability of and retaining customers, that is enabled by an IT application; for achieving mutual benefits for both the organization and the customers".

CRM is the technique or set of processes for collecting information from prospects and customers about their needs and for providing information that helps customers evaluate and purchase products that deliver the best possible value to them [7]. This definition outlines that CRM is a process meaning it requires time and procedures for managing company's resources that help in creating value for money for customers while generating revenue. Along the same lines [8], stipulate that CRM is a business strategy that goes beyond increasing transaction volume. Its objectives are to increase profitability, revenue and customer satisfaction. To achieve CRM, a company-wide set of tools, technologies and procedures promote the relationship with the customer to increase sales.

[9] propounded CRM as a customer-centric business strategy with the goal of maximizing profitability, revenue and customer satisfaction. A more popular approach with the recent application of information technology is to focus on individual or one-to-one relationships with customers that integrate database knowledge with a long-term customer retention and growth strategy [10]. As a business philosophy, [11] stated that "CRM is a relationship orientation, customer retention and superior customer value created through process management". The above definitions highlight the core goals of a company, which are: profit maximizing, increasing revenue, customer retention and customer satisfaction as well as involvement of technology. 


\section{Literature Review \\ 2.1 Customer Relationship Management paradigm \\ Customer Relationship Management can be divided into four separate branches, namely Strategic CRM, Analytical CRM, Operational CRM and Collaborative CRM [12].}

Strategic CRM: entails an enterprise wide strategy in which the main focus is on the customer. It is also assumed that, within an enterprise, it is a core managerial task to champion and implement this focus as a CRM strategy, including placing an emphasis on the systematic analysis and use of customer information as a platform for marketing and management [12].

Analytical CRM: refers to customer knowledge data base formed from the systematic collecting and storing of customer data is perceived as an asset to the enterprise. Through an analysis of the data in this data base it is possible to improve marketing efficiency in different ways. It is important that the ICT development has made it possible to both gather and analyse customer data in a much more systematic and efficient way than was previously the case before the computer revolution [12].

Operational CRM: means that an ICT based support is provided for front office activities, including sales, service and support. Such support is intended to be used both in call or contact centres and by the sales staff in their customer contacts. Along the same lines [13] cited in [14] also view it as the business processes and technologies that help improving the efficiency of day-to-day customers operations. Operational CRM includes sales, marketing and service automation.

Collaborative CRM: [12] support it as the development of ICT has opened up new possibilities for communicating with the customers. In addition to personal contacts, telephone contacts and mails, it is now also possible to communicate through web sites, e-mail, self-service telephone contacts, and SMS. Through this development, the use of different communication channels in a channel management strategy has become a branch of CRM. [13] cited in [14], stipulate that it manages all interactions between the firm and its customers (e-mails, face-to face interactions, voice technologies, etc.).

\subsection{CRM process}

The process can be defined as the way in which things are done within an organization. This definition implies that organizations have certain procedures they follow [15]. Along the same lines in the [16] articulates that CRM processes can also be defined as "the activities performed by the organization concerning the management of the customer relationship and these activities are grouped according to a longitudinal view of the relationship. The objective of CRM process is to form customers' perceptions of an organization and its products through identifying customers, creating customer knowledge, and building customers relationships.

\subsection{Conditions for CRM success}

An effective CRM should meet the following conditions:

\section{Collaboration}

Collaboration has already been claimed to be the fundamental property of relationships between suppliers and customers, competitors, consultants, government agencies and others. The collaboration can be linked to a single deal or be continuous. The degree of collaboration could be combined with the degree of competition .A situation with little competition and little collaboration between two or more companies can be a good start for expanded collaboration. A high degree of collaboration and low degree of competition provide a base for a long-term and harmonious relationship. Relationships can also thrive in a situation of both extensive collaboration and competition [17].

\section{Longevity}

[17] stipulates that it has been stressed that the long-term relationship is a pillar of Relationship Marketing. This is in opposition to transaction marketing, which is characterised by single deals and customer promiscuity. The concept of duration, retention and defection have been defined .Long- term relationships can be more effective for all parties especially if it takes a long time to build them a common case in. Switching costs may be high and no relationship should be broken because of negligence or lack of interest. The parties learn how to handle the relationship and utilize it to their benefit. According to [18], through research it is possible to identify the diverse factors that influence the consumer in the act of the purchase and in set with the administration of the relations with these important consumers they had become factor-key in the promotional reach of the organisational success and this supports longevity. However there are factors like pricing, brand 
credibility which affect longevity and this has to be taken note of as the scholars have not included this in their review when establishing long -term relationships in special regards within Rainbow Towers for success of the business.

\section{Commitment, dependence and importance}

[17] articulates that in a relationship the parties should be dependent on it and must commit themselves to make that relationship work because the parties benefit from such a relationship. The organization gains increased frequency of purchase and free adverts through the use of positive word of mouth. The customer gains reduced time of search and processing and also get products and services that are tailored to their individual needs. [19] stipulates that dependence has the greatest positive effect on commitment, because customers prefer to maintain relationships with sellers on which they depend .For example, increasing customer dependence can increase commitment but has a limited effect on trust, because customers grow concerned that the seller will take advantage of their dependence.

\section{Customer focused quality}

The whole units or functions in the organization should work together to deliver quality to the customer. Customer service should not be left to marketers only but it must be everyone's responsibility in the organization from the person who obtains food stock up to the person who delivers the product to the customer. Complete customer satisfaction is the key to securing customer loyalty and generating financial performance. Loyalty is based on the level of satisfaction. A drop in the level of satisfaction can be a drop in the level of loyalty. [1] support that quality help reduce costs hence it becomes important to involve suppliers and customers in implementing the program at all levels of the value chain.

\section{Attraction}

[17] stipulates that in the marriage metaphor of long term relationship, attraction between the parties is a dominant factor. Studies have shown that attraction between companies may require a combination of rational financial motives and psychological factors. Even in business a partner should be cool and sexy. This also applies for the image that companies convey through their brands. The importance of attraction for establishing relationships both within industries and to customers is perhaps nowhere more protruding than in entertainment, sports, tourism and politics. The main idea is that attraction is a dominant factor that pulls unlike poles to meet. In this case at Rainbow Towers the servicescape should be appealing as well as the brand.

\section{Routinisation}

A common complaint in marriage is the lack of romance and excitement after a period of passion the relationship turns into routine. Although it sounds dull, routine procedures may be conditional for efficiency and cost effectiveness both in commercial and marital relationships. However customers also abandon suppliers who show no interest in them. So there is a trade -off between routines and standard procedures for speed and low cost and the feeling that the relationships develop and live [17].The proposed model by [20] was adopted from [21] this indicates supporting conditions for CRM success and these include senior management support, knowledge management, service quality, technology and people.

\section{Service quality}

The first supporting condition for CRM implementation; has been defined in terms of customer satisfaction: the degree of alignment between customers' expectations and their perceptions of the service received. The customer should determine what aspects of the service are the most beneficial rather than the service provider dictating these aspects [22]. Poor service is the dominant reason for losing business. The core product alone is no longer enough, and service quality is stressed as the key to successful business. It is necessary to discover the customer's real requirements. Focusing on these key service issues will be reflected in customer satisfaction. An essential aspect of managing service quality is the identification of client expectations, and then designing the service system to focus on these requirements; that is what CRM is all about. Service quality is considered a critical determinant of competitiveness. Service quality can help an organization to differentiate itself from other organizations and gain a competitive advantage. Superior service quality is a key to improved profitability [23].

\section{Senior management support and leadership}

This is a critical for the success of any CRM process. The support must extend beyond verbal support or approval of expenditure for consultants or training. Senior management support must be active, visible and constant, because CRM processes are about changing staff attitudes and the culture of an organization and senior management has the biggest influence on attitudes and culture. Senior management's own attitude and 
behaviour towards customers and other business aspects has a direct impact on how other staff think and behave. Leadership is an essential component of any CRM project teamwork: It is the art of creating a supportive work environment. Team leaders must work with senior management to ensure that they create an organizational ambience that is conducive to the teams' needs [21].

\section{Information technology (IT)}

The third major supporting condition for CRM implementation is technology which is a key enabler, but is only a means to the end. It enables the whole business to see and serve customers in the same way through: Accessible data as well as efficient and consistent processes. The key is getting the balance of technology investment appropriate for the specific goals set out in the customer strategy. CRM systems must be able to operate in the office, out of the office and over the web. They must tie together multiple communication channels, each using very different technologies (web, e-mail, telephone). And they must be flexible to accommodate changing customer needs and demands [21].

\section{People}

The fourth supporting condition for CRM successful implementation is people. People's skills, knowledge and attitudes are essential elements for CRM performance. People also need to be trained in many competencies. People resist change because they do not see that it is in their self-interest. Management should benefit from this and consider it as useful information that tells them what is working and not working in the change process [24]. Management must ensure that job evaluations, compensation programs, and reward systems are modified on a basis that facilitates and rewards customer orientation [25].

\section{Knowledge management}

The fifth supporting condition is that knowledge is an entity that is a strategic business asset, and therefore the processes associated with it need to be managed. Some authors like [26] considered customer relationship management as an application of knowledge management. "Customer Relationship Management (CRM) is a strategy used to learn more about customers' needs and behaviours in order to develop stronger relationships with them. These conditions were acknowledged from a study that was carried out by [20].

\subsection{Sampling Techniques}

\section{Research methodology}

Purposive sampling was mainly used for flexibility in collecting data and also to eliminate unnecessary data. The technique gives space to identify important respondents for the research. Stratified random sampling technique was also used for the following reasons: to ensure that the sample will not have by any chance undue proportion of one unit in it. The population was big and therefore had to be divided into strata according to positions occupied within the organisation (i.e. managers, supervisors etc) and then the sample was picked randomly from each stratum. The population comprised of hotels in Harare, the capital city of Zimbabwe. A sample of 90 respondents was used in this study.

\subsection{Research design}

A descriptive research design was used for this study as it paves way for carrying out surveys and factfinding enquiries of different kinds [27]. [28] pointed out that the importance of a research design is to prepare a proper framework, within which the research work will be actually carried out and acts as a blue print. Consistent with [29] three principal research approaches, this study was exploratory in nature. The research design was descriptive in nature in that it attempted to provide a detailed description of contemporary CRM conditions within a specific context, that is, the hospitality sector. We used questionnaires in obtaining information from the respondents. Questionnaires were tailor made to cater for all the respondents on a five point Likert scale as a way to obtain more reliable, accurate and realistic information. All questionnaires were written in English. Personal interviews were carried out to obtain information from hotel managers. The study sample comprised of 90 respondents drawn from hotels in Harare metropolitan city.

\subsection{Descriptive statistics}

\section{Results}

Eleven items were used in establishing the conditions necessary for CRM success and the descriptive statistics are as shown in the table below; 
Table 1: Descriptive statistics (Conditions for CRM success)

\begin{tabular}{lccc}
\hline Variable & Mean & Standard deviation & Variance \\
\hline Interdepartmental Collaboration & 2.20 & .964 & .929 \\
Trust & 2.74 & .919 & .844 \\
Adaptation & 2.66 & .765 & .585 \\
Attraction & 2.34 & .998 & .997 \\
Routinisation & 2.49 & .919 & .845 \\
Knowledge management & 2.89 & 1.078 & 1.163 \\
Senior & 3.14 & 1.458 & 2.126 \\
management support and leadership & 2.54 & .980 & .961 \\
Service quality & 3.20 & 1.132 & 1.282 \\
Technology & 2.97 & 1.124 & 1.264 \\
Business plan and vision & 2.97 & 1.224 & 1.499 \\
Commitment, dependence & and & & \\
importance & & & \\
\hline
\end{tabular}

Scale: $1=$ strongly agree $2=$ Agree $3=$ Neutral $4=$ Disagree $5=$ =strongly agree

Conditions for CRM success were measured using eleven items adapted from [17] and [21].The respondents were required to indicate the supporting conditions that are provided by the hotel from a Likert scale of 1-5 (strongly agree- strongly disagree). Mean values range from 2 to 3 and this means the responses range from agree to neutral. The standard deviation above 0 are widely scattered beyond the mean and most variables are below 1 in the standard deviation and indicate that they are closely scattered to the mean. The overall descriptive results in Table 1 (above) show that technology (mean score=3.20) achieved the highest mean followed by senior management support and leadership (mean score=3.14). The lowest overall mean score are interdepartmental collaboration (mean score=2.20), followed by attraction (mean score=2.34).

\subsection{Factor analysis and Reliability analysis}

Factor analysis was done to address the problem of analyzing the structure of the interrelationships (correlations) among a large number of variables (e.g., test scores, test items, questionnaire responses) by defining a set of common underlying dimensions, known as factors. Reliability analysis was also done to check the consistency in the measurement scale [30]. Cronbach alpha $(\alpha)$ was used for reliability analysis as it is an easy and generally acceptable estimate of reliability [30]. The recommended minimum acceptability value for $\alpha$ is 0.70 , although some studies use $\alpha$ as low as 0.50 [31]. This study used Cronbach alpha score of 0.50 as it was a new measure. Results of the factor and reliability analyses are as shown in Table 2 below;

Table 2: Factor analysis and reliability analysis

\begin{tabular}{|c|c|c|c|c|c|c|}
\hline Construct & Item & Factor 1 & Factor 2 & Factor 3 & Factor 4 & Test \\
\hline $\begin{array}{l}\text { Supporting } \\
\text { conditions for } \\
\text { CRM }\end{array}$ & & & & & & Cronbach alpha .745 \\
\hline $\begin{array}{l}\text { Operational } \\
\text { conditions }\end{array}$ & $\begin{array}{l}\text { A5 } \\
\text { A6 } \\
\text { A8 } \\
\text { A11 }\end{array}$ & $\begin{array}{l}.662 \\
.689 \\
.656 \\
.521 \\
\end{array}$ & & & & Cronbach alpha .703 \\
\hline $\begin{array}{l}\text { Technological } \\
\text { conditions }\end{array}$ & $\begin{array}{l}\text { A3 } \\
\text { A7 }\end{array}$ & & & $\begin{array}{l}.465 \\
.694 \\
\end{array}$ & & Cronbach alpha.539 \\
\hline
\end{tabular}

Table 2 is a summarisation of the responses of many items showing their reliability. The initial process of scale validation involved factor analysis. The conditions for CRM success were made up of 11 items.Factor analysis resulted in 4 factors emerging which are service conditions, operational conditions, human conditions and technological conditions. Overally supporting conditions for CRM had a Cronbach alpha score of 0.745 which show a high level of consistency. The operational conditions measured what they intended to measure with a Cronbach alpha score of 0.703 . Technological conditions were significant with Cronbach alpha score of 0.539 . Human and Service conditions were not significant and were eliminated because they produced Cronbach alpha score less than 0.5 which proved that they were not reliable.

\section{Discussion and Implications}

This study was attempted using both quantitative and qualitative methods with chi-square test and thematic analysis respectively. 


\subsection{Quantitative analysis}

The conditions for CRM success were made up of 11 items. Factor analysis resulted in 4 factors emerging which are service conditions, operational conditions, human conditions and technological conditions as shown in table 2. Chi-square test was done to measure the conditions for CRM success.The results for chisquare are depicted below:

Table 3: Chi-square test results (Conditions for CRM success)

\begin{tabular}{lcccc}
\hline & Service conditions & Operational conditions & Human conditions & Technological conditions \\
\hline Chi-Square & $8.543^{\mathrm{a}}$ & $19.171^{\mathrm{b}}$ & $14.429^{\mathrm{c}}$ & $14.143^{\mathrm{b}}$ \\
Df & 11 & 7 & 9 & 7 \\
Asymp. Sig. & .664 & .008 & .108 & .049 \\
\hline
\end{tabular}

The above table indicates that technological conditions and operational conditions proved to be significant with $\mathrm{X}^{2}(14.143)$ and $\mathrm{X}^{2}(19.171)$ at $\mathrm{p}<0.05$ respectively. Descriptive statistics showed a significant variation in respondents' views towards technology with a majority $(48.5 \%)$ disagreeing on the presence of this condition whereas $28.6 \%$ were indifferent and $22.9 \%$ said these conditions were available. Service and human conditions statistically show that there is no significant difference. This is supported by [32] who note that in CRM success, the infrastructural factors, management attitude and information technology (IT) are highly evaluated, since management support is a critical factor for successful innovation, CRM as an organizational innovation also requires management's strong impetus and support.

Moreover, visible advancement in the level of IT triggered by the CRM implementation project could be considered as a critical success factor (CSF) in that IT is one of the key resources in organizations for sustainable competitive advantage [33]. Thus, organizations are required to integrate IT to improve the capabilities of understanding customer behaviour, develop predictive models, build effective communications with customers and respond to those customers with real time and accurate information [25].

\subsection{Qualitative analysis}

Qualitative analysis for this study was done using thematic analysis on responses from the key informant interviews. The respondents identified collaboration within departments, attraction of the servicescape as the critical supporting conditions for CRM success.

\section{Theme 1: Collaboration among departments}

Respondents noted that collaboration among departments is important in determining CRM success. This concurs with what [21] review as the supporting conditions for CRM Success. In a similar study by [34] this factor focuses on the integration of different departments and areas of the organisation to meet the general objectives of CRM and the main company's objectives as well as the objectives of the departments.

\section{Theme 2: Servicescape}

The respondents highlighted that attraction of the servicescape is vital in CRM success. [17] view attraction of the servicescape as an important supporting condition for CRM Success. The importance of attraction for establishing relationships both within organisations and to customers is perhaps nowhere more protruding than in entertainment, sports, tourism and politics. Thus in the marriage metaphor of long term relationship, attraction between the parties is a dominant factor.

\section{Theme 3: Online correspondence and Guest questionnaire collection}

Guest feedback, online correspondence and hosting cocktails for long staying guest and top suppliers emerged as an additional dimension in the hospitality industry which has not been stated in most literature. [35] support the notion that numerous hotel chains provide their high-value and preferred customers with room upgrades and even free mini-bar usage as well as adhering to online customer management as a way to create a conducive environment for CRM success.

\section{Conclusions and Implications}

The resolution of the Hospitality sector in Zimbabwe lies in the promotion and enhancement of CRM conditions. There is need for the Hospitality sector to source funding and resources for CRM. Few respondents confirmed that technological and human conditions are present in the Hospitality sector in Zimbabwe, hence the need for organizations to improve their CRM conditions. Organizations are required to integrate IT to improve the capabilities of understanding customer behaviour, develop predictive models, build effective 
communications with customers and respond to those customers with real time and accurate information [25]. New methods incorporating state of-the-art technology will need to be mastered and creative approaches required to understand customer behaviour in differing international cultural contexts also need to be developed [36]. Management should set the direction and maintain the conviction that the customer is the centre of the business. Without a CRM business plan and vision, the percentage chance for CRM initiative failure remains high [37].

\section{References}

[1] Parvatiyar, A and Sheth, J.N, Preliminary issue Emerging practice, process and discipline. Journal of economic and social research, vol 3(2), 2000; 2001, 1-344.

[2] Berkowitz, Customer Relationship Management, 8 Common goals for a CRM Program, What are Key Drivers Of Customer Satisfaction? [Online] Available at: http://onlinesuccesscentre.com, 2006.

[3] Amoako, G.K., Arthur, E., Bandoh, C and Katah, R.K, African Journal of Marketing Management, Vol. 4(1), 2012 , 17-29.

[4] Lun, Z., Jinlin, L and Yingying, W, Customer relationship management system framework design of Beijing Rural Commercial Bank. IEEE International Conference on Service Operations and Logistics and Informatics (SOLI 2008), 2008, 97-101.

[5] Rababah, K., H. Mohd and H. Ibrahim, A unified definition of CRM towards the successful adoption and implementation. In the 3rd Lifelong Learning International Conference (3LInC'10), Kuala Lumpur, Malaysia, 2010.

[6] Maroofi, F., Aliabadi., B., Fakhri, M and Hadikolivand, H, Asian Journal of Business Management, Vol 5(1), 2013, 52-59.

[7] Christopher, M and Peck, H, Marketing Logistics, 2nd Edition, (Butterworth Heinemann, 2003)

[8] Bhattarcharjee, C, Services Marketing Concepts, Planning and Implementation, First Edition, (New Delhi, 2006)

[9] Gartner, Inc, CRM retail Study: A survey conducted by the National Retail Federation, (United States, 2004)

[10] Peppers, D and Rogers, M, The One to One Manager: Real-World Lessons in Customer Relationship Management,(Doubleday, New York, 1993)

[11] Ryals, L and Adrian, P, Customer relationship management in financial services: Towards information enabled relationship marketing, Journal of Strategic Marketing, vol 9, 2001, 3-27.

[12] Walberg, O. and Strandberg, C, SME marketing and the adoption of the CRM approach. - On the relevance of the CRM approach for SME marketing and propositions about barriers to adoption of the approach. Proceedings of the 5th International conference on small and medium sized enterprises, 11-14 August 2008, (Athens, 2008).

[13] META Group, Integration: Critical Issues for Implementing of CRM Solutions, (META Group, 2001)

[14] Durand and Bouzidi, The Alignment between Customer Relationship Management and IT Strategy, Proceedings of the Southern Association for Information Systems Conference, Richmond, VA, (USA March 13th-15 ${ }^{\text {th }}, 2008$ )

[15] Payne, A. and Frow, P, A, Strategic Framework for Customer Relationship Management, Journal of Marketing, vol 69, October, 2005, pp167-176.

[16] Journal of Personal Selling and Sales Management spring, Vol 28(2), 2009.

[17] Gummerson, E, Total Relationship Marketing, Marketing Management, relationship strategy, Customer Relationship Management and a new dominant logic for value-creating network economy, $3^{\text {rd }}$ Edition, (Butterworth Heinemann, USA, 2008).

[18] Asian Pacific Journal of Research in Business, vol 2(6), 2011, 293 and 297.

[19] Palmatier, R.W, Relationship Marketing, Marketing Science Institute, (USA, 2008)

[20] Ali, I, Customer relationship management: A qualitative Cross-Case Analysis in the UK and Saudi Arabia, (Scotland, 2007).

[21] Buttle, F. Customer relationship management: concepts and technologies. $2^{\text {nd }}$ ed. (Oxford: Butterworth-Heinemann, 2009).

[22] Babakus, E. and Boller, G.W, An empirical assessment of the SERVQUAL scale', Journal of Business Research, Vol. 24, 1992, 253-68.

[23] Ghobadian, A., Speller, S. and Jones, M, Service quality concepts and models, Journal of Marketing, vol 51 (April), $1994,11-27$.

[24] Brendler, W, The human dimension of CRM: The key success or failure, The Customer relationship primer [Online] Second edition, Available: www.crmguru.com, 2001

[25] Chen, I. J. and Popovitch, K, Understanding customer relationship management (CRM), Business Process Management Journal, Vol. 9(5), 2003

[26] Chou, D and Lin, B, Development of web-based knowledge management systems. Human Systems Management, vol 21, 2002, 153-61.

[27] Kothari, C.R. Research Methodology: Methods and Techniques, $2^{\text {nd }}$ edition, (New Age Techno Press Publishers, New Delhi India, 2004).

[28] Kumar, R, Research Methodology, (APH Publishing Corporation, New Delhi, 2008).

[29] Yin, R. K, Case Study Research: Design and Methods, 2nd edition, (Sage Publications, Thousand Oaks, California, 1994).

[30] Field, A, Discovering Statistics using SPSS, Second Edition, (Sage Publications, New Delhi, 2005).

[31] Nunnally, J, Psychometric Theory, New York, NY: (McGraw-Hill, 1978).

[32] Sharma, R., and Yetton, P, The contingent effects of management support and task interdependence on successful IS implementation. MIS Quarterly, vol 27(4), 2003, 533-555.

[33] Bharadwaj, S.G., Varadarajan, R. and Fahy, J, Sustainable competitive advantage in service industries: A conceptual model and research, Journal of Marketing, vol 57(4), 1993, 83-99.

[34] Almotairi, M, A framework for successful CRM implementation, European Mediterranean Conference on information systems, July 13-14 2009, (Crown Plaza Hotel, Izmir, 2009).

[35] Baran, R., Zerres, C., and Zerres, M, Customer Relationship Management, London, (Ventus Publishing Aps, Holstebro, 2008).

[36] Craig, C.S. and Douglas, S.P, Conducting international marketing research in the twenty-first century, International Marketing Review, Vol. 18 No. 1, 2001, 80-90.

[37] Roche, E, Avoiding CRM Program Failures, To Truly Design Around the Customer, Defying the Limits, vol 4, 2003, pp 64-66. 